\title{
Hospitalary outbreak of Burkholderia cepacia bacteremia associated with a decrease of chlorination of water system
}

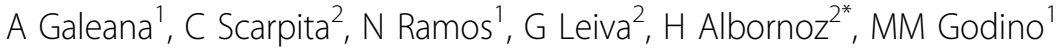 \\ From International Conference on Prevention \& Infection Control (ICPIC 2011) \\ Geneva, Switzerland. 29 June - 2 July 2011
}

\begin{abstract}
Introduction
Burkhordelia Cepacia (BC) complex is a genomicrelated group of gram negative bacilli. Haemato oncological (HO), and dialysis patients (pts) are especially vulnerable to microorganisms that contaminate the hospital environment, especially water.
\end{abstract}

\section{Objectives}

Report a clonal prolonged outbreak of bacteraemia by $\mathrm{BC}$ in a tertiary hospital in Uruguay.

\section{Methods}

Description and analysis of the outbreak, genetic identification of the organism by molecular biology and communicating the interventions.

\section{Results}

Between 27/3/2008 and 3/2/2008, 4 pts in the HO unit developed $\mathrm{BC}$ bacteremia.

In March 2008, 6 ptes developed chills during haemodialysis (HD), blood cultures didn't grow BC. At 15/4/ 2008 another patient in $\mathrm{HO}$ unit developed bacteraemia by $\mathrm{BC}$.

In the $\mathrm{HO}$ unit the molecular biology confirmed a clonal outbreak. The crops of antiseptic solutions, soap, tap water, and bottled water showed no growth of $\mathrm{BC}$.

Measurements of the levels of chlorine in tap water was less than or equal to $0.25 \mathrm{ppm}$. Subsequently the chlorination deficit was confirmed at the water system throughout the hospital.

The final molecular biology analysis confirmed the clonality of the bacteremia in the $5 \mathrm{HO}$ pts, one peak of dialysis (11 and 19 March), a HD machine and the tip of a dialysis catheter. A shock chlorination of the water system of hospital was performed.

\section{Conclusion}

- A prolonged, and spreaded clonal outbreak of BC was manifested in the pts who are especially vulnerable.

- The organism was identified in ptes and devices, and in the water system associated with decreased chlorination, .

- The chlorination of the water system was an effective measure to control the outbreak.

\section{Disclosure of interest}

None declared.

\section{Author details}

${ }^{1}$ Hospital Maciel, Uraguay. ${ }^{2} F N R$, Montevideo, Uruguay.

Published: 29 June 2011

doi:10.1186/1753-6561-5-S6-O76

Cite this article as: Galeana et al: Hospitalary outbreak of Burkholderia cepacia bacteremia associated with a decrease of chlorination of water system. BMC Proceedings 2011 5(Suppl 6):076.

${ }^{2}$ FNR, Montevideo, Uruguay

Full list of author information is available at the end of the article

C 2011 Galeana et al; licensee BioMed Central Ltd. This is an open access article distributed under the terms of the Creative Commons Attribution License (http://creativecommons.org/licenses/by/2.0), which permits unrestricted use, distribution, and reproduction in any medium, provided the original work is properly cited. 